\title{
The relationship between 100Cr6 steelmaking, inclusion microstructure and rolling contact fatigue performance
}

\author{
Hanwei Fu ${ }^{\mathrm{a}}$, Jakub Jelita Rydel ${ }^{\mathrm{b}}$, Adam M. Gola ${ }^{\mathrm{b}}$, Feng Yu ${ }^{\mathrm{d}}$, Ke Genge, \\ Chenghan Lau ${ }^{\mathrm{a}}$, Haiwen Luo ${ }^{\mathrm{c}}$, Pedro E. J. Rivera-Díaz-del-Castilloa,* \\ ${ }^{a}$ Department of Engineering, Engineering Building, Lancaster University, UK, LA1 $4 Y W$ \\ ${ }^{b}$ Department of Materials Science and Metallurgy, 27 Charles Babbage Rd., University of \\ Cambridge, UK, CB3 OFS. \\ ${ }^{c}$ School of Metallurgical and Ecological Engineering, University of Science and Technology \\ Beijing, Beijing 100083, China. \\ ${ }^{d}$ Central Iron and Steel Research Institute, 76 Xue Yuan Nan Rd., Beijing 100081, China. \\ ${ }^{e}$ Jiangyin Xingcheng Special Steel Works Co. Ltd., 297 Binjiang East Rd., Jiangyin City, \\ Jiangsu 214429, China.
}

\begin{abstract}
A processing-microstructure-performance approach is followed to study three bearing steel samples manufactured from the most frequently used continuous casting routes. The inclusion microstructures of the samples were altered by varying the metallurgy and hot working conditions. Inclusion size distribution information is obtained, showing the steel-making route that results in the highest cleanliness. 3D analysis of inclusion morphologies using electrolytic extraction indicates the irregularities on the surface to be favourable sites for crack nucleation under RCF. Flat-washer and ball-on-rod tests were conducted to study the rolling contact fatigue life of the steels, with the results from the flatwasher testing method being more representative for bearing life. This research suggests that early fatigue of bearings is governed by silicate fragmentation and late fatigue by TiN inclusions.
\end{abstract}

Keywords: Bearing steels, inclusion analysis, rolling contact fatigue, bearing life analysis

\footnotetext{
${ }^{*}$ Corresponding author

Email address: p.rivera1@lancaster.ac.uk (Pedro E. J. Rivera-Díaz-del-Castillo)
} 


\section{Introduction}

Bearing steels subjected to extreme service environment such as high contact pressure, high rotational speed and sometimes elevated temperature are exposed to rolling contact fatigue (RCF), which is the key factor affecting bearing life [1]. RCF is categorised into two mechanisms: surface-induced RCF and subsurfaceinduced RCF 2]. When surface-induced RCF operates, cracks initiated from the contact surface cause pitting on the raceway [3]. Surface initiated cracks usually propagate with a shallow angle $\left(15^{\circ}-30^{\circ}\right)$ to the surface if observed from the circumferential section of a fatigued specimen [4. During surface-induced $\mathrm{RCF}$, crack initiation is found to take place at very early stage of bearing life, whilst the total life is mainly dependent upon crack propagation, the growth rate of which is proved to follow a Paris-type power law [3]. The occurrence of surface-induced failure is favoured by sliding [ $[$, thus affected by conditions such as surface roughness and oil film thickness [6, 7]. Nonetheless, surface-induced $\mathrm{RCF}$ can be theoretically eliminated for properly lubricated bearings where elastohydrodynamic lubrication (EHL) is achieved [5]; then subsurface-induced RCF becomes predominant. According to Hertzian theory 8, under rolling contact shear stress components peak at the subsurface, which is believed to be responsible for subsurface-induced RCF [9]. In RCF tests accelerated by high contact pressures, matrix martensite transitions such as dark etching regions (DERs) 10 or white etching bands (WEBs) 11 are often observed, whereas cracks initiated at non-metallic inclusions (NMIs) are more detrimental to bearing life under normal bearing operation conditions 12. NMIs acting as stress concentrators promote crack initiation and subsequent propagation, which is believed to be associated with early failure 13, 14. These cracks are sometimes accompanied by white etching areas (WEAs) [15, a phase harder than 
the parent matrix and formed as a consequence of crack surface rubbing [1. As indicated by the unique inclination of subsurface crack with respect to the over-rolling direction $\left(\sim 45^{\circ}\right)$, the maximum shear stress is considered to be the responsible stress component [16, 17, 18. Attempts [19, 20, 21] have been made using various modelling techniques to predict subsurface crack formation, but the complexity of this issue calls for better insight into NMIs effects. It is generally believed that bearing life is dependent upon the size and number density of NMIs 22, 23, 24, 25, while it is further proved that inclusion-matrix bonding also plays a role 26]. The type of NMIs thus becomes crucial 27]. NMIs originate from the steel-making process and their microstructure is modified by hot working, which causes elongation of soft inclusions (e.g. MnS), fragmentation of brittle inclusions (e.g. silicates) or the formation of voids around hard inclusions (e.g. alumina) 28, 29, 30, 31, 27. Conventional evaluation of NMIs ranks the harmfulness of different types of inclusions 32, but this is just a crude estimation.

As for bearing life, industry adopts a probabilistic approach to quantify the factors influencing bearing life. Such approach is embodied in the following equation 33 :

$$
L_{n}=a_{1} a_{2} a_{3} \cdots a_{i}\left(\frac{D}{P}\right)^{p}
$$

where $L_{n}$ is the number of cycles with $n \%$ bearing failure probability, $D$ is the dynamic load capacity, $P$ is the equivalent radial load on bearings, $p$ is an exponent that varies with bearing geometry, $a_{1}$ is the reliability constant, $a_{2}$ is a constant related to the material fatigue properties and $a_{3}$ is a constant related to the lubricant. Coefficients related to other aspects of bearings are also embedded into Equation (1) as $a_{i}$. The steelmaking route is implicitly incorporated in these coefficients, which are fitted to experiments, offering no insight into the microstructural factors influencing bearing life. With the development 
of steel metallurgy and purification, modern bearing steels are able to achieve rather high cleanliness, and hence become sensitive to those NMIs conventionally considered non detrimental, such as silicates and TiN [26. Moreover, owing to the extended life of super-clean bearing steels, the type of NMIs responsible for subsurface-initiated RCF may alter at different life stages. In this research, investigation was conducted here to reveal the nature of the harmfulness of different types of NMIs throughout processing/microstructure/performance aspects. Super-clean bearing steels manufactured with various steelmaking routes are studied, in order to establish a relationship between steelmaking and inclusion microstructure and life.

\section{Experimental}

\subsection{Material and manufacturing routes}

The material studied in this research is 100Cr6 (SAE 52100) bearing steel. Three batches of steel samples were produced at full industrial scale following three most frequently used industrial steel-making routes, summarised in Figure 1. denoted Route 1, Route 2 and Route 3. Routes 1 and 3 have the same metallurgical process (from basic oxygen furnace (BOF) to Rurhstahl Heraeus degasser (RHD)). Upon subsequent hot working, Route 1 was hot rolled to a reduction ratio in area of $97 \%$, whilst Route 3 was hot rolled to a reduction ratio in area of $93 \%$; as for Route 2, electric arc furnace (EAF) followed by vacuum degasser (VD) was adopted for the metallurgy, with the final hot rolling reduction ratio in area being $86 \%$. The final products from the three routes were with the same dimensions, steel bars of $60 \mathrm{~mm}$ diameter. The actual compositions of the samples from the three routes were confirmed by optical emission spectroscopy and are listed in Table 1. 


\begin{tabular}{|c|c|c|}
\hline Route 1 & Route 2 & Route 3 \\
\hline BOF - RHD & $E A F-V D$ & BOF - RHD \\
\hline$\downarrow$ Continuous casting & $\downarrow$ Continuous casting & $\downarrow$ Continuous casting \\
\hline Slab & Slab & Slab \\
\hline$\downarrow$ & $\sqrt{ }$ Blooming & $\downarrow$ Blooming \\
\hline Billet $(55 \%)$ & Billet (81\%) & Billet $(80 \%)$ \\
\hline $\boldsymbol{V}$ Rolling & $\downarrow$ Rolling & $\boldsymbol{V}$ Rolling \\
\hline $\begin{array}{c}\text { Ф60 mm bar } \\
(97 \%)\end{array}$ & $\begin{array}{c}\text { Ф60 mm bar } \\
(86 \%)\end{array}$ & $\begin{array}{c}\text { Ф60 mm bar } \\
(93 \%)\end{array}$ \\
\hline
\end{tabular}

Figure 1: Three steel-making routes employed in this research. The numbers in brackets represent reduction ratio in area.

Table 1: Chemical composition of the investigated steels.

\begin{tabular}{|c|c|c|c|c|c|c|c|c|c|}
\hline Route & $\begin{array}{c}\mathrm{C} \\
\text { (wt.\%) }\end{array}$ & $\begin{array}{c}\mathrm{Cr} \\
\text { (wt.\%) }\end{array}$ & $\begin{array}{c}\mathrm{Ni} \\
\text { (wt.\%) }\end{array}$ & $\begin{array}{c}\mathrm{Mn} \\
\text { (wt.\%) }\end{array}$ & $\begin{array}{c}\mathrm{Si} \\
\text { (wt.\%) }\end{array}$ & $\begin{array}{c}\text { Mo } \\
\text { (wt.\%) }\end{array}$ & $\begin{array}{c}\mathrm{Cu} \\
\text { (wt.\%) }\end{array}$ & $\begin{array}{c}\mathrm{P} \\
(\mathrm{ppm})\end{array}$ & $\begin{array}{c}\mathrm{S} \\
(\mathrm{ppm})\end{array}$ \\
\hline 1 & 0.95 & 1.50 & 0.02 & 0.01 & 0.27 & 0.01 & 0.02 & 130 & 20 \\
\hline 2 & 0.99 & 1.45 & 0.06 & 0.02 & 0.27 & 0.02 & 0.08 & 150 & 20 \\
\hline 3 & 0.96 & 1.44 & 0.02 & 0.01 & 0.26 & 0.01 & 0.02 & 40 & 20 \\
\hline $\begin{array}{c}\mathrm{Al} \\
(\mathrm{ppm})\end{array}$ & $\begin{array}{c}\mathrm{Ti} \\
(\mathrm{ppm})\end{array}$ & $\begin{array}{c}\mathrm{Ca} \\
(\mathrm{ppm})\end{array}$ & $\begin{array}{c}\mathrm{Pb} \\
(\mathrm{ppm})\end{array}$ & $\begin{array}{c}\text { Sn } \\
(\mathrm{ppm})\end{array}$ & $\begin{array}{c}\mathrm{As} \\
(\mathrm{ppm})\end{array}$ & $\begin{array}{c}\mathrm{Sb} \\
(\mathrm{ppm})\end{array}$ & $\begin{array}{c}\mathrm{Bi} \\
(\mathrm{ppm})\end{array}$ & $\begin{array}{c}\mathrm{N} \\
(\mathrm{ppm})\end{array}$ & $\begin{array}{c}\mathrm{O} \\
(\mathrm{ppm})\end{array}$ \\
\hline 247 & 6 & 2 & 16 & 10 & 20 & 10 & 30 & 20.3 & 6.1 \\
\hline 150 & 8 & 5 & 10 & 79 & 52 & 31 & 10 & 45.7 & 4.6 \\
\hline 212 & 6 & 3 & 20 & 10 & 17 & 10 & 20 & 23.9 & 6.4 \\
\hline
\end{tabular}

\subsection{Evaluation of inclusions}

Metallographic sections were cut for inclusion analysis according to ISO 4967 standard, with the sections being parallel to the bars' long axis. Prior to sectioning, the specimens were quenched and tempered for easier specimen preparation and better preservation of the inclusion microstructures. The sections were subsequently ground with abrasive papers and polished with diamond paste to achieve a mirror finish, adequate for scanning electron microscopy (SEM) analysis. No etching was performed during the analysis.

The samples were analysed with an ASPEX automated SEM equipped with 
an energy-dispersive X-ray (EDX) detector. For each detected inclusion its size, position and chemical composition were recorded and stored for further analysis. Inclusion size was automatically converted to Feret diameter which has a similar physical meaning to $\sqrt{\text { area }} 32$. Unusually large $116.6 \mathrm{~mm}^{2}$ sections were investigated. The inclusions' compositions were obtained from the EDX spectra and the following elements were considered in the analysis: $\mathrm{Na}, \mathrm{Mg}, \mathrm{Al}$, $\mathrm{Si}, \mathrm{S}, \mathrm{Cl}, \mathrm{K}, \mathrm{Ca}, \mathrm{Ti}, \mathrm{V}, \mathrm{Mn}, \mathrm{Fe}, \mathrm{Nb}$. All inclusions smaller than $2 \mu \mathrm{m}$ were excluded. Subsequently the inclusions were categosised into 6 groups according to the following rules:

- Sulphides: $\mathrm{Ca}+\mathrm{Mn}+\mathrm{S} \geq 50$ at $\%$

- Aluminates: $\mathrm{Mg} \geq 16.7$ at\% and $\mathrm{Al} \geq 33.3$ at $\%$ and aspect ratio $>3$

- Silicates: $\mathrm{Si} \geq 50$ at $\%$

- Globular oxides: $\mathrm{Al} \geq 50$ at\% and aspect ratio $<3$

- Titanium nitrites: $\mathrm{Ti} \geq 50$ at $\%$

- Unclassified: all remaining

By this simplified categorisation, only $13 \%$ of the inclusions remained unclassified.

In addition to the statistical analysis of inclusions, the morphologies of different types of inclusions were also studied by electrolytic extraction. Rod samples with a diameter of $6 \mathrm{~mm}$ and a height of $30 \mathrm{~mm}$ cut from the centre of the steel bars. Prior to electrolytic extraction, the samples were held at $1100{ }^{\circ} \mathrm{C}$ for 4 $\mathrm{h}$ to dissolve the carbides, followed by oil quench. The electrolytic-extraction device is schematically shown in Figure 2 The electrolyte was composed of 30 $\mathrm{g}$ of $\mathrm{FeSO}_{4}, 10 \mathrm{~g}$ of $\mathrm{NaCl}$ and $20 \mathrm{~g}$ of $\mathrm{C}_{6} \mathrm{H}_{6} \mathrm{Na}_{2} \mathrm{O}_{7}$ dissolved in $1000 \mathrm{ml}$ of distilled water. The electrolytic extraction was performed with a constant electric 


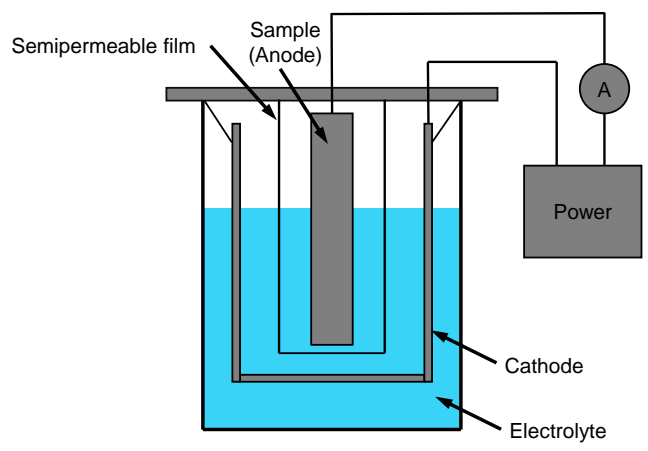

Figure 2: Schematic of the electrolytic-extraction device.

current density of $0.05 \mathrm{~A} / \mathrm{cm}^{2}$. During the electrolytic process, small inclusions were precipitated on the surface of the steel sample while large inclusions fell into the electrolyte and were captured by a semipermeable film. The test was suspended after a period of time, and then the small inclusions were scraped from the steel sample and collected along with the electrolyte containing the large inclusions. Subsequently, the inclusions were filtered with an opening size of $1 \mu \mathrm{m}$, followed by cleaning with ethanol. The dried inclusion particles were then characterised by SEM. The composition of inclusions was determined by EDX. The electrolytic extraction of inclusions allows for three-dimensional (3D) characterisation of inclusions.

\section{3. $R C F$ tests}

Two traditional RCF testing methods were employed to study RCF life, ballon-rod and flat-washer. The principles of the test rigs are schematically shown in Figure 3. For both methods, the ring and rod specimens were cut from the bar samples in such a way that the contact surface was perpendicular to the hot rolling axis. Prior to the tests, The RCF specimens were first quenched from the 
(a)

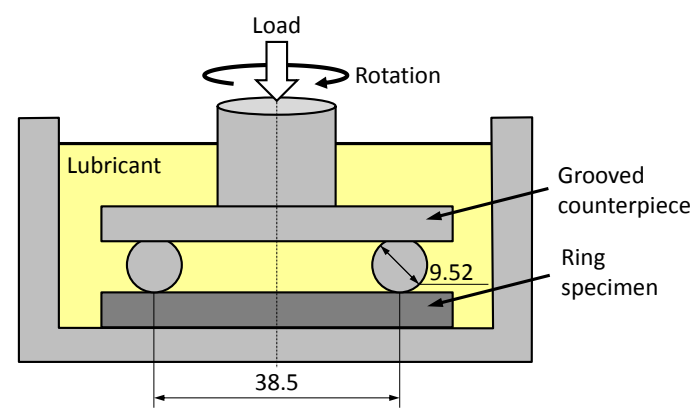

(b)

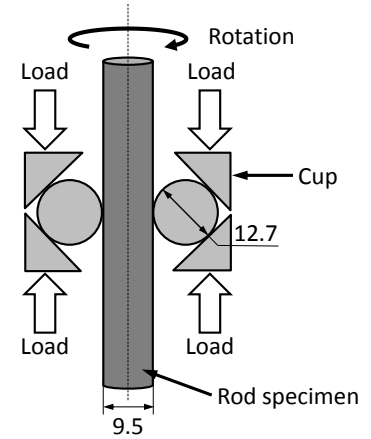

Figure 3: Schematic illustration of flat-washer (a) and ball-on-rod (b) RCF rigs. All dimensions are in $\mathrm{mm}$ (dimensions not to scale).

austenitisation temperature of $840^{\circ} \mathrm{C}$ to room temperature and tempered at 160 ${ }^{\circ} \mathrm{C}$ for $90 \mathrm{~min}$, which is a standard heat treatment for commercial martensitic bearings. The heat treatment resulted in an average hardness of $62 \mathrm{HRC}$ in all the three cases. The surface roughness of the RCF specimens was carefully controlled. Before RCF testing, the surface roughness $\left(R_{a}\right)$ is $0.63 \mu \mathrm{m}$ for all ring specimens and $0.12 \mu \mathrm{m}$ for all rod samples. The For each steel making route, 20 flat-washer tests and 10 ball-on-rod tests were conducted. For flatwasher, the tests were carried out under a maximum contact pressure $\left(p_{0}\right)$ of 4.5 GPa with a rotational speed of $1500 \mathrm{rpm}$, and for ball-on-rod under a maximum contact pressure of $4.2 \mathrm{GPa}$ with a rotational speed of $3600 \mathrm{rpm}$. All the tests were conducted at room temperature with sufficient lubrication. BT Turbo Oil was used as lubricant, with its density being $975 \mathrm{~kg} / \mathrm{m}^{3}$ and its kinematic viscosity being $24.3 \mathrm{~mm}^{2} / \mathrm{s}$ at the testing temperature. Each test was stopped when failure (spalling) manifested as an abrupt increase in vibration (monitored through a vibration sensor), or when $10^{8}$ cycles were reached. 


\subsection{Post RCF characterisation}

The tracks of fatigued specimens were studied by optical microscopy (OM) to determine the failure modes of the specimens. The tracks were cut to show their central sections below the contact surfaces. The sections were ground with abrasive papers and polished with diamond paste to achieve a mirror finish before the OM investigation on the spalls. The polished sections were then etched by $2 \%$ nital solution for further study of the microstructure.

\section{Results and discussion}

\subsection{Inclusion evaluation results}

Figure 4 presents the results from the inclusion analysis. The Feret diameter distribution for different inclusion classes can be found in Figures 4 (a) to (f), along with the number density and the maximum size of all classes summarised in Figures 4 (g) and (h), respectively. According to Figure 4(h), Routes 1 and 3 exhibit similar maximum inclusion size for all inclusion classes, especially the conventional detrimental inclusion types, aluminates and globular oxides. This should be attributed to the same metallurgical process in the two routes. Nevertheless, silicates exhibit significantly different distribution in the three routes. For Route 2 and 3, in Figure 4(c), only one major inclusion size can be observed, whilst for Route 1 a considerable amount of silicates can be seen in a wide range of sizes, especially small sizes. This indicates silicate fragmentation in Route 1. As for Route 2, the maximum size of silicates, globular oxides, titanium nitrides and unclassified inclusions is different from the other two routes, given the different metallurgical process. Especially, the maximum size of globular oxides and titanium nitrides is significantly larger in Route 2. It should also be noted that Route 1 experienced the highest reduction ratio in area during hot rolling among the three and therefore silicate fragmentation occurs. 
(a)
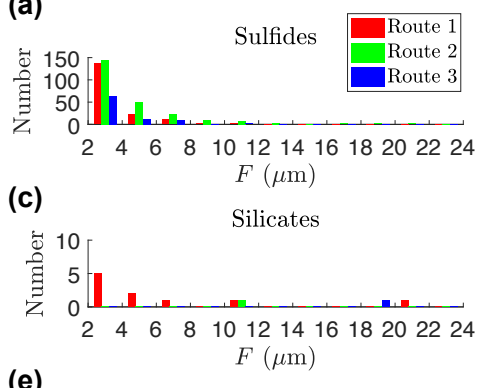

(e)

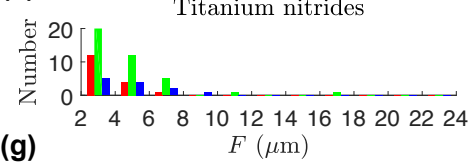

(g)

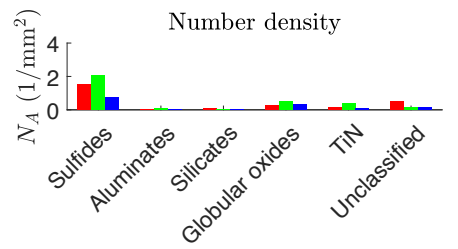

(b)
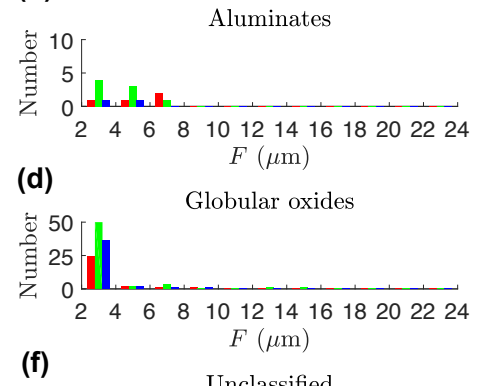

$50 \quad$ Unclassifie

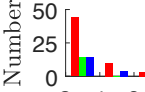

(h)

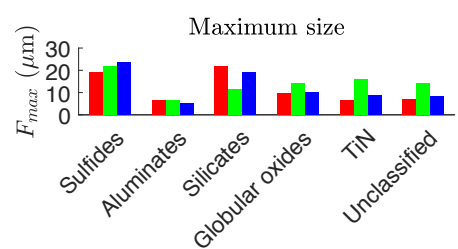

Figure 4: Size histograms of inclusions (a-f), the number density of inclusions (g) and maximum inclusion size (h). The legend given in (a) applies to all sub-figures.

Figure 5 shows the typical morphologies obtained from electrolytic extraction. The four types of inclusions which are most frequently found are presented, and their typical size is similar, $3-5 \mu \mathrm{m}$, agreeing with the statistical analysis in Figure 4. Nevertheless, it can be seen that the inclusions of different types vary significantly in morphology. The MnS particle shown in Figure 5 (a) exhibits an elliptical shape, and its smooth boundary is illustrated by the yellow curve. Such morphology stems from the high deformability of MnS [32. However, for hard or brittle inclusions, irregular boundaries are frequently observed. These irregularities are pointed out by the yellow arrows:

- The $\mathrm{Al}_{2} \mathrm{O}_{3}$ particle in Figure 5 (b) has numerous cavities on its surface.

- The $\mathrm{SiO}_{2}$ particle in Figure 5 (c) contains a significant cleavage indicating fragmentation. 
- The TiN particle in Figure 5 (d) shows sharp edges around it.

Such irregularities within the inclusions, or at their interfaces with the matrix may constitute features detrimental to bearing life.
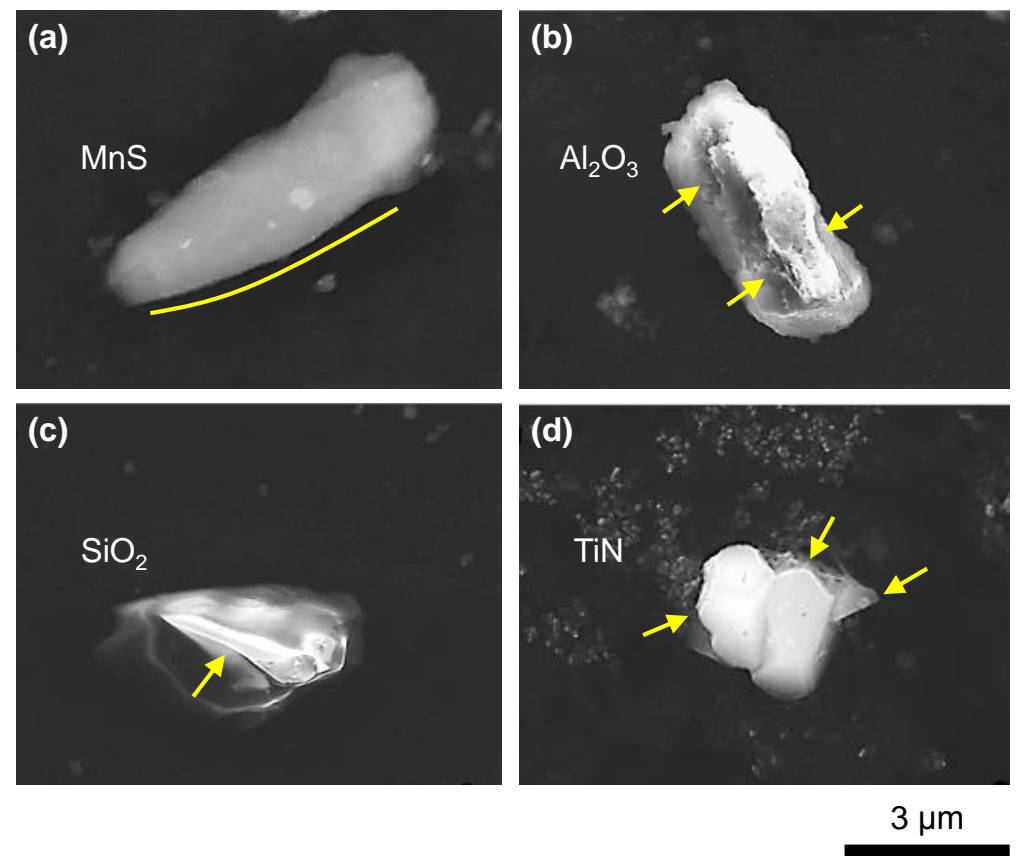

Figure 5: Morphologies of different types of inclusions obtained from electolytic extraction.

\subsection{RCF testing results}

Figures 6 (a) and (b) present the the failure probability plots together with fitted Weibull distributions of the three routes from the flat-washer and ball-onrod testing, respectively. The Weibull parameters are estimated using the best linear invariant estimator (BLIE) method, with the $95 \%$ confidence intervals presented in Figures 6 (c) and (d) for the two RCF testing methods. Overall, the lives of the samples from the ball-on-rod tests are longer than those from the flat-washer tests, due to lower $p_{0}$. As shown in Figure6 (a), it can be seen that a relatively significant difference in life between the three steel-making routes 
can be obtained by the flat-washer method whilst there is almost no observable difference in life during the ball-on-rod tests (Figure 6 (b)). This indicates that the flat-washer test is more sensitive to minor differences in material than the ball-on-rod test for such high cleanliness steels. According to Figure 6 (a), Route 1 exhibits the worst performance at the low probability regime, whereas at the high probability regime, Route 2 becomes the worst of the three. Also, Route 3 outperforms Route 2 at all regimes. Table 2 lists the $L_{10}$ and $L_{50}$ values obtained from the RCF tests along with the corresponding Weibull slopes.

(a)

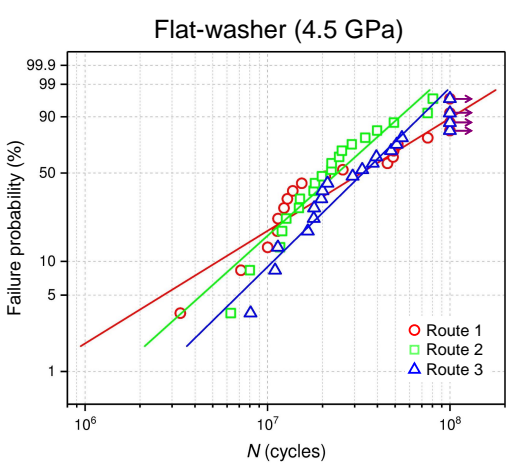

(c)

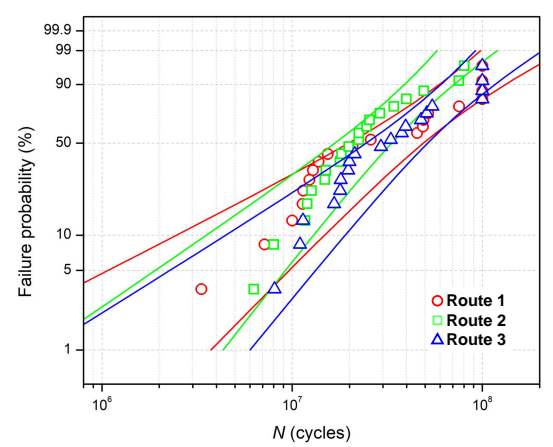

(b)

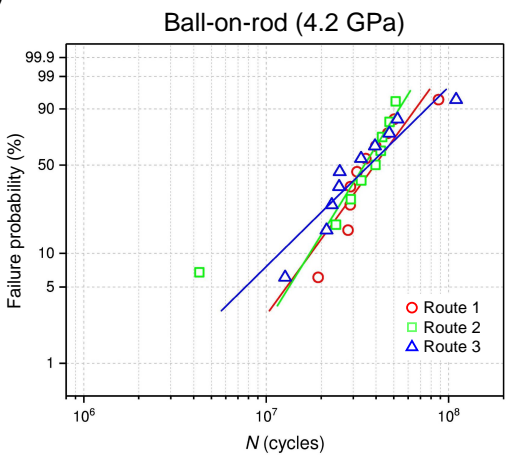

(d)

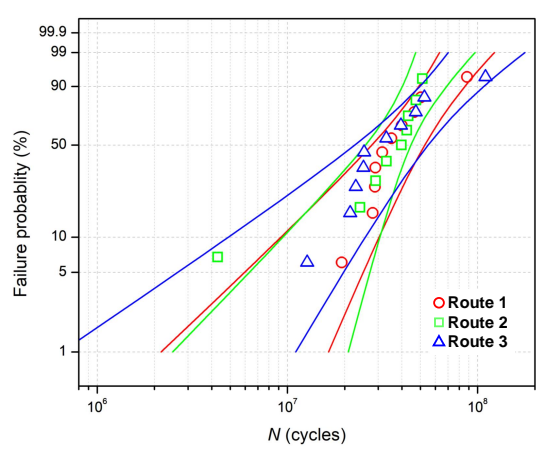

Figure 6: RCF failure probability data and Weibull fitting for flat-washer tests (a) and ballon-rod tests (b). (c) and (d) $95 \%$ confidence intervals for the Weibull fitting of the flat-washer test data and the ball-on-rod test data, respectively. The colors of the bound lines accord with those of the routes. 
Table 2: $L_{10}, L_{50}$ and Weibull slopes of the tested steels from different RCF testing methods

\begin{tabular}{cccccc}
\hline & $p_{0}(\mathrm{GPa})$ & Route & $L_{10}($ cycles $)$ & $L_{50}$ (cycles) & $\beta$ \\
\hline \multirow{3}{*}{ Flat-washer } & \multirow{3}{*}{4.5} & 1 & $5.35 \times 10^{6}$ & $3.26 \times 10^{7}$ & 1.04 \\
& & 2 & $6.98 \times 10^{6}$ & $2.41 \times 10^{7}$ & 1.52 \\
& & 3 & $1.07 \times 10^{7}$ & $3.34 \times 10^{7}$ & 1.66 \\
\hline \multirow{3}{*}{ Ball-on-rod } & \multirow{2}{*}{4.2} & 1 & $1.76 \times 10^{7}$ & $3.94 \times 10^{7}$ & 2.34 \\
& & 2 & $1.73 \times 10^{7}$ & $3.45 \times 10^{7}$ & 2.74 \\
& & 3 & $1.18 \times 10^{7}$ & $3.67 \times 10^{7}$ & 1.67 \\
\hline
\end{tabular}

\subsection{Post RCF characterisation results}

Figure 7 illustrates the fatigued tested ring and rod specimens and the corresponding testing tracks. On each track, there is always a significant spall which caused the stop of the test. Optical microscopic observation of the spalls is shown in Figure 8 . Figures 8 (a) and (b) shows a spall located at the centre of the track after $4.5 \times 10^{7}$ cycles on a Route 3 ring specimen. No significant plastic deformation was found at the contact surface. Figure 8 (c) shows the track after $5.1 \times 10^{7}$ cycles on a Route 2 rod specimen. In this case, numerous small pits can be observed at the contact surface. The major spall on this track is shown in Figure 8 (d). The dashed lines in Figure 8 (b) and (d) illustrate the centre of the tracks where they were sectioned for crack observation.

Figure 9 (a) shows the polished centre section of the track after $1.3 \times 10^{7}$ cycles with a spall on a Route 3 rod specimen. The over-rolling direction (ORD) during the test is indicated by the arrow. At the edge of the spall, the crack propagate at an angle of $\sim 30^{\circ}$ with respect to over-rolling direction, indicating a surface initiated RCF mechanism. Subsurface cracks can also be found from the spall and the crack propagation direction is often parallel to the contact surface. Figure 9 (b) shows a magnified subsurface cracked region at the edge of the spall after etching, consisting of a major crack and several branches. Figures 9 (c) and (d) show another cracked region of the spall before and after etch- 


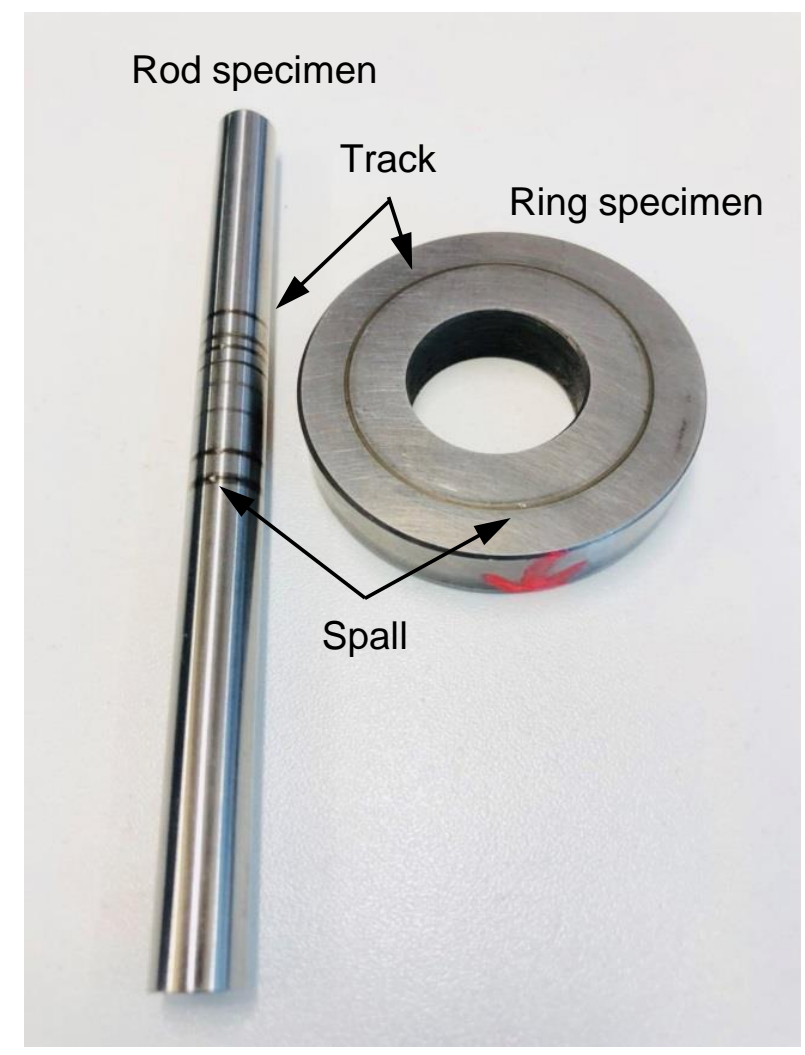

Figure 7: RCF specimens.

ing. It seems that kinking upon crack propagation follows some microstructural features. None of the investigated cracks was accompanied by a white etching areas.

Figure 10 (a) shows the polished centre section of a track after $4.5 \times 10^{7} \mathrm{cy}-$ cles on a Route 3 ring specimen. The spall also has a shallow crack propagation angle, indicating a surface-induced RCF mechanism. Whereas in Figure 10 (b), cracks propagate from the subsurface towards the contact surface. Figures 10 (c) and (d) illustrate the cracked regions of the spall after etching.

Figure 11 presents the study on crack propagation behaviour under rolling contact fatigue. Figure 11 (a) is from a Route 2 rod specimen track after $5.1 \times$ $10^{7}$ cycles; Figures 11 (b) and (c) are from a Route 3 rod specimen track after 

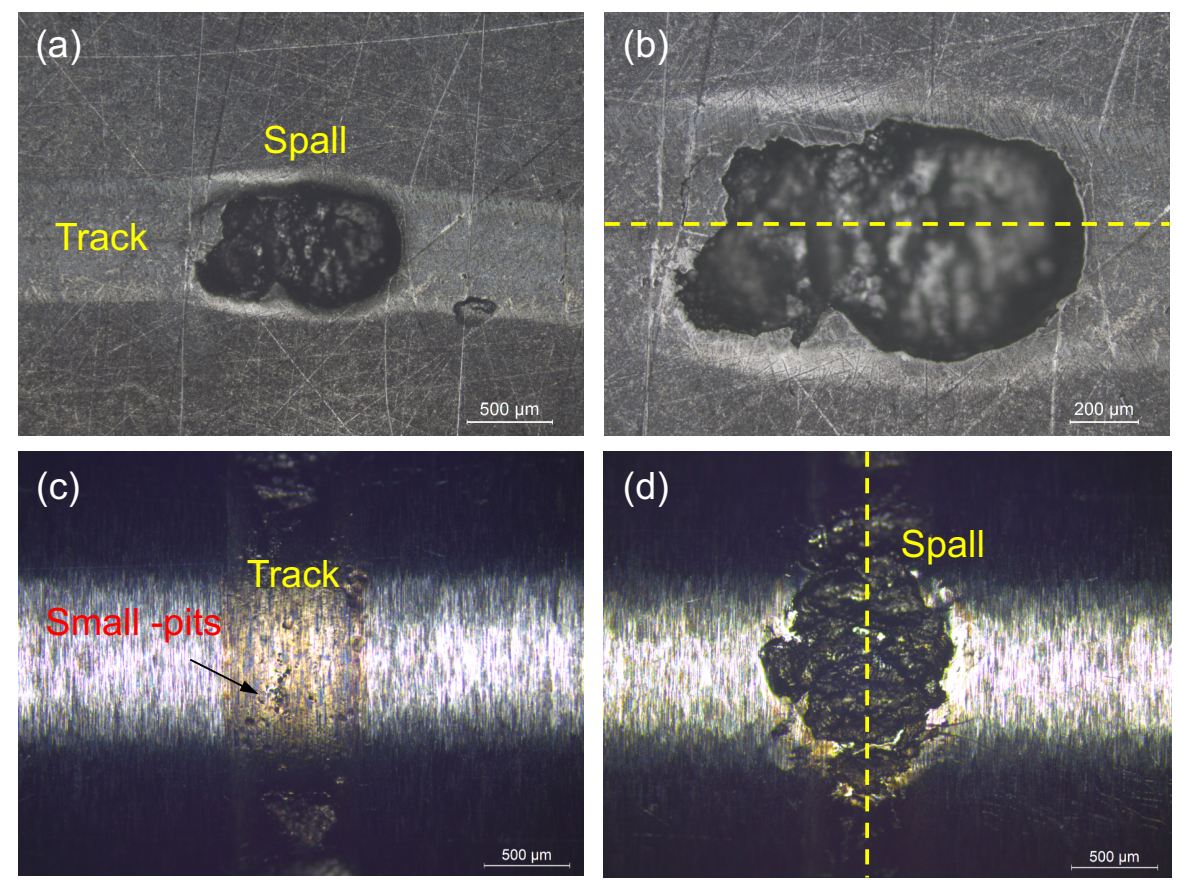

Figure 8: Optical microscopic images of testing tracks and spalls from flat-washer test ((a) and (b)) and from ball-on-rod test ((c) and (d)).

$5.2 \times 10^{7}$ cycles; Figure 11 (d) is from a Route 3 ring specimen track after 4.5 $\times 10^{7}$ cycles. In all these optical microscopic images, crack branches can be clearly seen under high magnification and the branches proceed following prioraustenite grain boundaries, indicating that the prior-austenite grain boundaries are the weakest part of the matrix.

Figure 12 (a) presents a crack formed at the subsurface of a fatigued rod specimen. No spalling was observed on the track above this crack. This is strong evidence showing subsurface-induced rolling contact fatigue. The propagation path of this crack is shown in Figure 12 (b). It can be seen that this subsurface crack also proceeds following prior-austenite grain boundaries.

\subsection{Discussion}



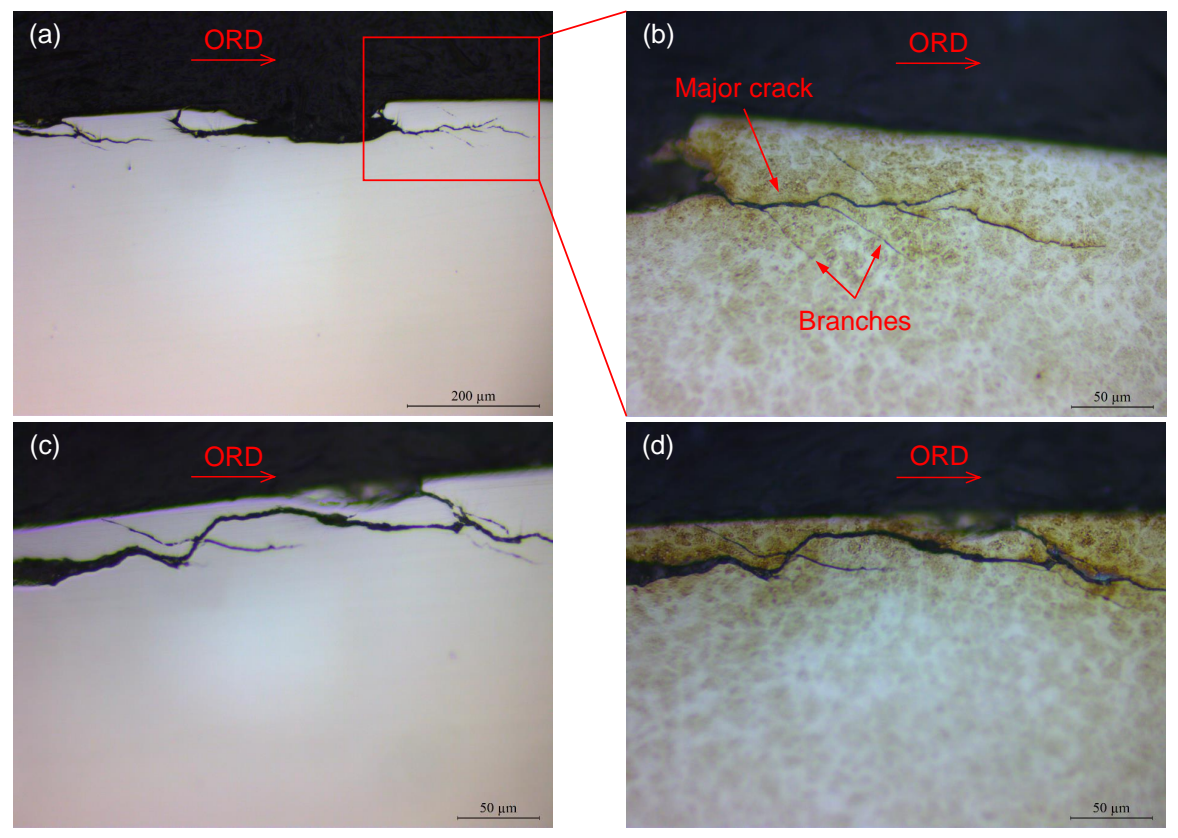

Figure 9: Optical microscopic images from a Route 3 sectioned rod specimen after polishing. (a) Geometry of the spall formed after $1.3 \times 10^{7}$ cycles. (b) A crack parallel to the contact surface. (c) Cracked region before etching. (d) Cracked region in (c) after etching.

As studied in the post RCF characterisation, evidence of surface-induced crack propagation is found on the rod specimens. However, the presence of subsurface cracks as illustrated in Figure 12 suggests that subsurface induced fatigue mechanism also operates during the ball-on-rod tests. For flat-washer, the circumferential sections also indicate both surface- and subsurface-induced fatigue mechanisms operating. The effect of surface-induced RCF should be the same on all the tests for either ball-on-rod testing or flat-washer testing, as the surface conditions are carefully controlled to be identical. Therefore, the differences in life between different routes should stem from the differences in inclusion microstructure. The inclusion microstructrues of the steel routes result from the variations in metallurgy and reduction ratio. According to the inclusion analysis, Routes 1 and 3, which were produced by the same metallur- 

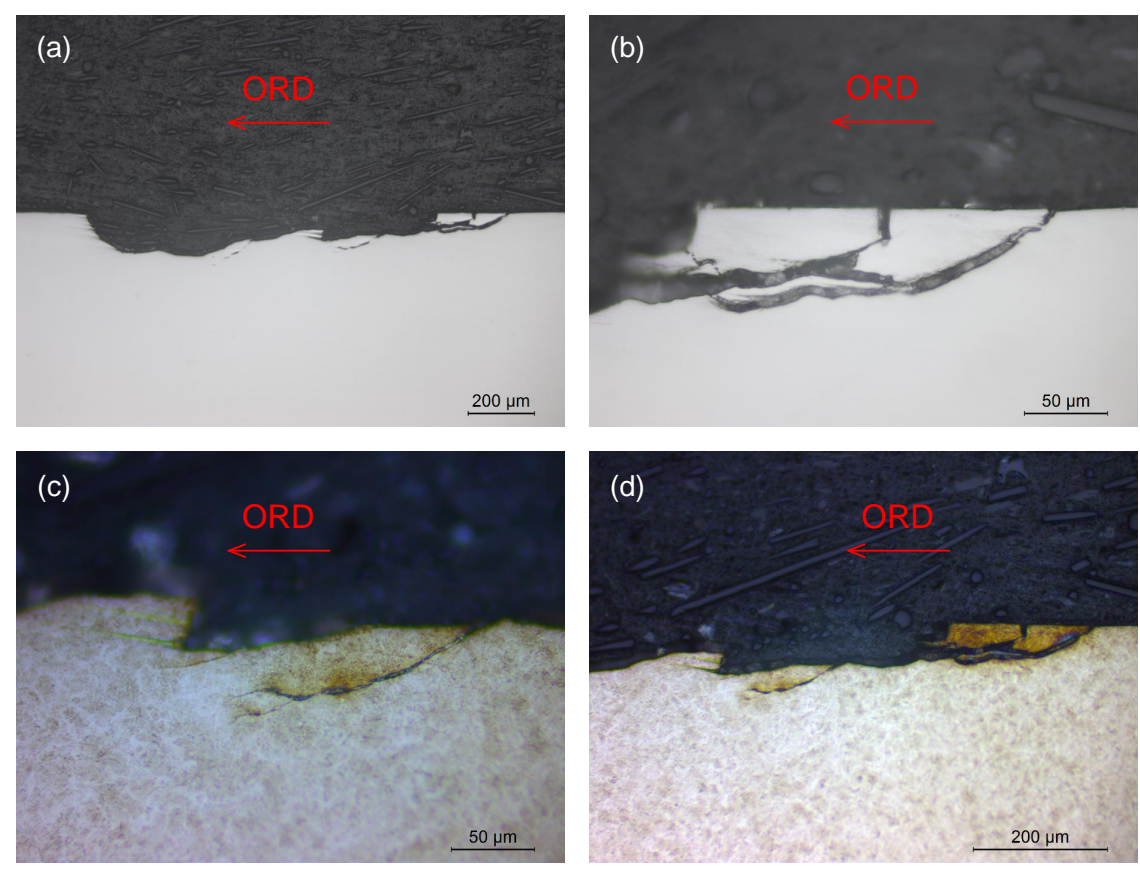

Figure 10: Optical microscopic images from a Route 3 sectioned ring specimen after polishing. (a) Geometry of the spall formed after $4.5 \times 10^{7}$ cycles. (b) Cracks propagating towards the contact surface. (c) and (d) Cracked regions after etching.

gical process, have similar number density and maximum size of inclusions of all types, whilst Route 2 is significantly different, with generally larger inclusions. The results also indicate the BOF-RHD metallurgy method produces cleaner products than the EAF-VD method. It is believed that the maximum size of inclusions is the determining factor in bearing life. Referring to the RCF results in Figure 6 (a), Route 2 exhibits the worst performance at the high probability regime, which may be due to its largest maximum size of globular oxides and titanium nitrides. Considering that globular oxides, mainly composed of $\mathrm{Al}_{2} \mathrm{O}_{3}$, are favourable crack nucleation sites at the early and medium stages of bearing life, the bad performance of Route 2 at high probability regime may be attributed to titanium nitrides. Nevertheless, previous understanding is that TiN do not affect RCF life [32, 4]; this could be due to titanium nitrides, although 

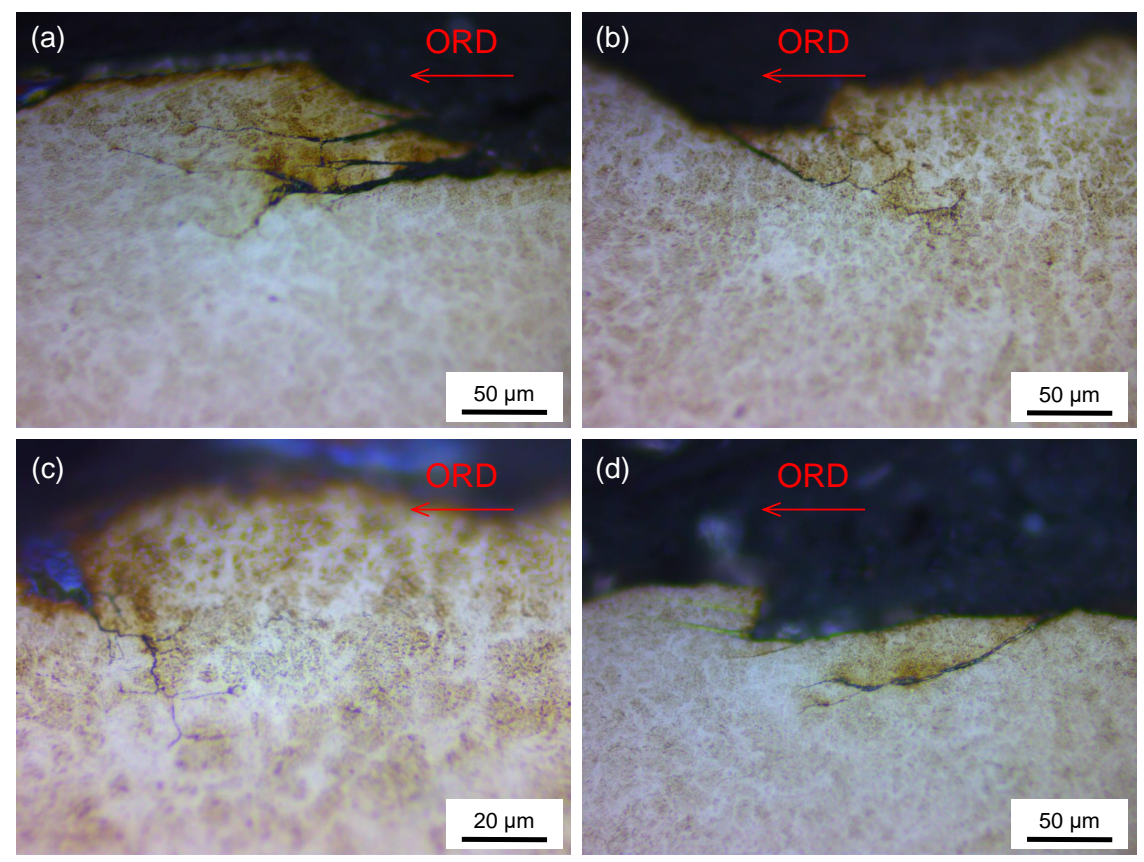

Figure 11: Crack branches under high magnification showing their propagating traces. (a) Route 2 rod after $5.1 \times 10^{7}$ cycles. (b) and (c) Route 3 rod after $5.2 \times 10^{7}$ cycles. (d) Route 3 ring after $5.2 \times 10^{7}$ cycles.
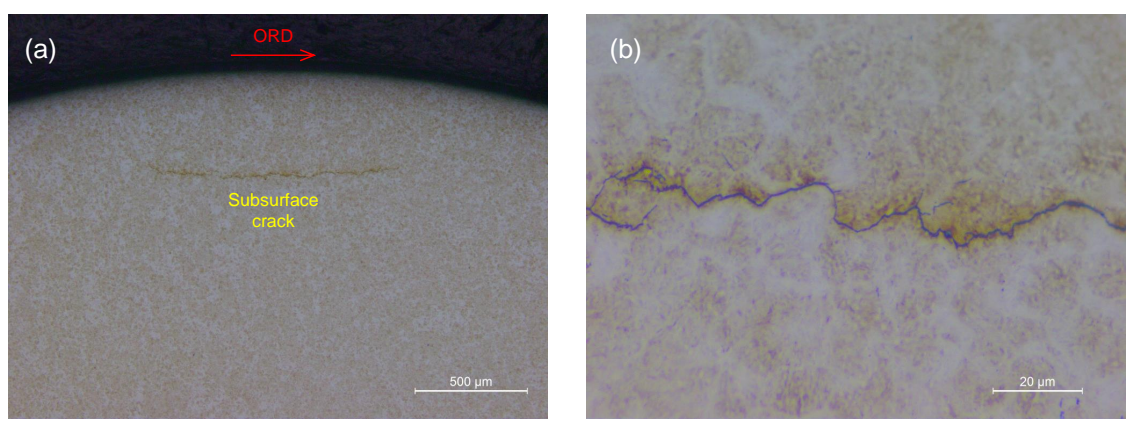

Figure 12: A subsurface crack formed in a Route 2 sectioned rod specimen after etching. The test was stopped after $4.5 \times 10^{7}$ cycles (a) Crack location at subsurface. (b) Crack propagation path.

with sharp edges to initiate cracks easily, do not sufficiently concentrate stress so as to reach a critical length for their propagation. When the steel cleanliness is low, other types of inclusions with incoherent interface with matrix, such 
as globular aluminates, can not only initiate cracks easily at the early stage but also concentrate sufficient stress at their vicinity to promote propagation [17, 27. Hence the cracks initiated from titanium nitrides cannot even reach the contact surface before the cracks initiated form globular aluminates already result in failure. However, when steel cleanliness is high, the chance that the stress affected volume meets large globular aluminates becomes much lower, and once the test endures to a very high number of cycles ( $>10^{7}$ cycles) at such high stress level (4.5 GPa), the cracks initiated from titanium nitrides may start fast propagation, eventually leading to failure. Thus the effect of titanium nitrides on RCF life can be identified at such high-cycle conditions. Additionally, surface-induced RCF occurs in all cases and becomes more probable at the high cycle regime, which could mask the effect of TiN on life.

Another interesting result from the flat-washer tests is the bad performance of Route 1 at the low probability regime. This can be attributed to its unique size distribution of silicates. Owing to the largest reduction ratio in area amongst the three routes, Route 1 is the only one exhibiting silicate fragmentation. Silicate fragments cannot form coherent interfaces with the matrix and should be regarded as voids during RCF [18]. Moreover, silicate fragmentation results in a high number density of such voids which could be favourable crack nucleation sites. The results indicate that silicate fragmentation controls early failure of bearings.

As for the ball-on-rod tests, no significant difference between the Weibull curves of the three routes can be detected by this method. This may be due to the failure mode of the tests. The failure mode of RCF tests is indicated by the value of the Weibull slope $(\beta)$. It is generally thought that for $\beta \in[1.5 ; 2.5]$ the failure mode is likely to be fatigue, and for $\beta \in[3 ; 4]$, the failure mode is likely to be wear, tear or corrosion [34. The typical $\beta$ value for ball bearings is 
about 1.5 [35]. According to Table 2, the results from the flat-washer tests are more representative for bearing fatigue, and the large $\beta$ values from the ballon-rod tests indicate that surface-induced fatigue mechanism is predominant in controlling life. Comparing the two RCF testing methods, it seems that the ball-on-rod testing method is less sensitive to minor differences in inclusion microstructure of different bearing steels. This could be due to the difference in stress-affected volume in the two methods. As calculated from Hertzian theory 8, The stress-affected volume in flat-washer testing is about 3.5 times larger than of ball-on-rod testing, which means the expected number of inclusions encountered per unit time is much higher in the former case. Moreover, the elastohydrodynamic lubrication conditions for the two methods in this research are assessed by $\lambda$, the ratio between the minimum lubricant film thickness and the sample roughness [36, with the former determined by contact pressure, contact geometry and lubricant properties. In this research, for the flat-washer method, the minimum oil film thickness is $0.122 \mu \mathrm{m}$ and $\lambda=1.2$; for the ball-onrod method, the minimum oil film thickness is $0.087 \mu \mathrm{m}$ and $\lambda=0.9$. According to the criterion 1, when $\lambda<1$, specimen undergoes partial metal to metal contact with ball; when $1<\lambda<3$, the degree of metal to metal contact is limited; when $\lambda>3$, metal to metal contact is eliminated. Therefore, in this research, the metal to metal contact between specimen and ball occurs under both methods, but the ball-on-rod method is more prone to surface-induced $\mathrm{RCF}$, which could be another reason for its poor sensitivity to the difference in inclusion microstructures. Although such minor difference from the ball-on-rod tests is not evident using the Weibull method, an alternative statistical method is adopted. In Fiugure 13, the percentage of failed tests grouped into three stages is presented for both methods. For the flat-washer method, the early stage is defined to be $<10^{7}$ cycles, the medium stage $10^{7}-5 \times 10^{7}$ cycles and 
the late stage $>5 \times 10^{7}$ cycles. For the ball-on-rod tests, due to the lower contact pressure level, the early stage is defined to be $<2 \times 10^{7}$ cycles, the medium stage $2 \times 10^{7}-6 \times 10^{7}$ cycles and the late stage $>6 \times 10^{7}$ cycles. The results clearly show that in both cases, Route 2 displays a shorter life as it led to the smallest number of samples failed during the RCF tests at the late stage. The ball-on-rod tests indicate that Routes 1 and 3 give the exactly same result in Figure 13 , but the flat-washer tests reveals that Routes 1 and 3 have the same probability to fail at the late stage but Route 3 has the lower probability to fail at the early stage.

(a)

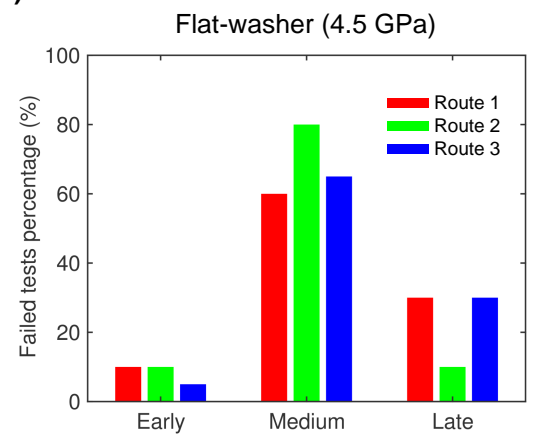

(b)

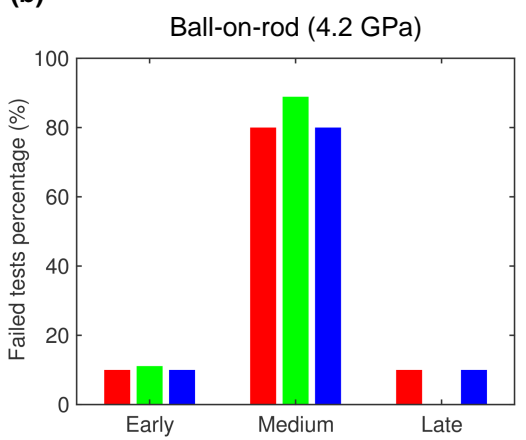

Figure 13: Percentage of failed RCF tests grouping into three stages. (a) Flat-washer tests, the early stage $<10^{7}$ cycles, the medium stage $10^{7}-5 \times 10^{7}$ cycles and the late stage $>5$ $\times 10^{7}$ cycles. (b) Ball-on-rod tests, the early stage $<2 \times 10^{7}$ cycles, the medium stage $2 \times$ $10^{7}-6 \times 10^{7}$ cycles and the late stage $>6 \times 10^{7}$ cycles.

Furthermore, the stress state under RCF was calculated based on Hertzian theory [8. Surface friction is not taken into consideration for the calculation due to the difficulty in measuring the friction coefficient. Figures 14 (b) and (d) show the distribution of von Mises stress $\left(\sigma_{V M}\right)$ at the subsurface for the flat-washer method and the ball-on-rod method, respectively. In comparison to the spalls from the two methods, the depth of the spalls agrees with where the maximum $\sigma_{V M}$ is achieved, confirming the subsurface-induced fatigue mechanism operating in both cases. It should be noted as well that regardless of $p_{0}$, 
the maximum $\sigma_{V M}$ under ball-on-rod is closer to the contact surface than that under flat-washer testing. Although the presence of surface friction may alter the symmetry of the stress field, the depth of maximum $\sigma_{V M}$ is almost not affected.
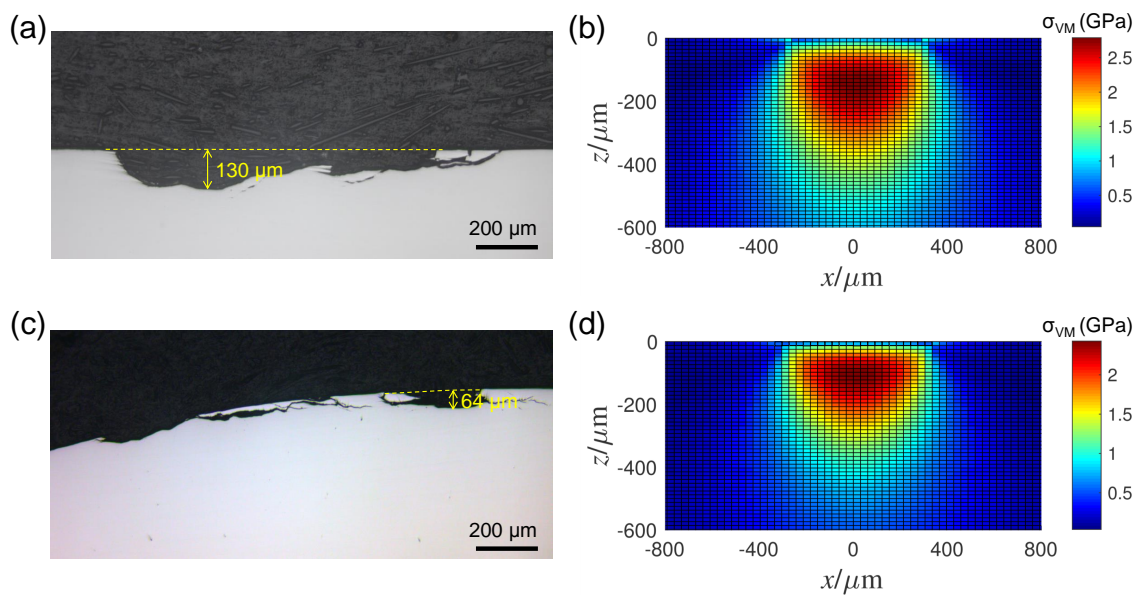

Figure 14: Stress state calculated for RCF tests. (a) and (c) Optical microscopic images of the geometries of the spalls from ring and rod specimens, respectively. (b) and (d) Calculated von Mises stress distribution for ring and rod specimens, respectively. Note surface friction is not taken into consideration for the calculation.

Finally, it is worth noticing that no microstructrual alterations (white etching areas, dark etching regions or white etching bands) [16, 10, were found in any fatigued specimens from this research. This could be due to the low RCF testing temperature which is insufficient to activate effective carbon-dislocation interaction for strain-induced carbon redistribution [37, 38, 39].

\section{Summary}

Super-clean 100Cr6 bearing steel bar samples manufactured at full industrial scale following three most frequently used routes (Routes 1, 2 and 3) have been systematically studied. A processing-microstructure-performance procedure is employed. The key points are summarised as follows: 
- The maximum size of inclusions of different types is mainly determined by the metallurgic process while the subsequent hot working affects their size distribution. The largest size of globular oxides and titanium nitrides is found in Route 2 (EAF-VD wit $86 \%$ reduction ratio in area) and silicate fragmentation is found in Route 1 (BOF-RHD wit $97 \%$ reduction ratio in area).

- Electrolytic extraction was conducted to study the morphologies of different types of inclusions in 3D. MnS particles are found with a smooth profile and are therefore not detrimental to bearing component life, whereas $\mathrm{Al}_{2} \mathrm{O}_{3}$ particles, TiN particles and silicates have obvious irregularities on the surface, acting as favourable sites for crack nucleation.

- RCF tests were carried out using flat-washer and ball-on-rod methods. The results were analysed by Weibull distribution and post RCF characterisation was conducted as well. Although both surface- and subsurfaceinduced RCF mechanisms operate in both RCF testing methods, it is found that the flat-washer method is more sensitive to minor differences in inclusion microstructure. Route 1 (BOF-RHD wit $97 \%$ reduction ratio in area) exhibits the worst performance at the low failure probability regime and Route 2 (EAF-VD wit $86 \%$ reduction ratio in area) exhibits the worst performance at the high probability regime.

- Crack propagation under RCF in bearing steels follows the prior-austenite grain boundaries, which are the weakest part of the matrix with the greatest misorientation .

- Different from previous understanding on the effects of TiN inclusions and silicates, this research suggests that early fatigue of bearings is governed by silicate fragmentation and late fatigue by TiN inclusions. The presence 
of surface-induced RCF may mask the effect of TiN at the high probability

regime.

\section{Acknowledgement}

This work was financed by grant EP/MS07817/2 from the UK Engineering and Physical Science Research Council (EPSRC) and by the Ministry of Science and Technology China, Project No. 2015DFGS1950. PEJRDC is grateful to SKF for the provision of financial support early on this project, and to the Royal Academy of Engineering for supporting a Research Chair.

\section{References}

[1] H. K. D. H. Bhadeshia, Steels for bearings, Prog. Mater. Sci. 57 (2) (2012) 268-435.

[2] A. Olver, The mechanism of rolling contact fatigue: an update, Proc. Inst. Mech. Eng., Part J 219 (5) (2005) 313-330.

[3] P. Rycerz, A. Olver, A. Kadiric, Propagation of surface initiated rolling contact fatigue cracks in bearing steel, Int. J. Fatigue 97 (2017) 29-38.

[4] D. Nélias, M. L. Dumont, F. Champiot, A. Vincent, D. Girodin, R. Fougeres, L. Flamand, Role of inclusions, surface roughness and operating conditions on rolling contact fatigue, J. of Tribol. 121 (2) (1999) $240-251$.

[5] F. Sadeghi, B. Jalalahmadi, T. S. Slack, N. Raje, N. K. Arakere, A review of rolling contact fatigue, J. Tribol. 131 (4) (2009) 041403.

[6] J. Liu, T. Tallian, J. McCool, Dependence of bearing fatigue life on film thickness to surface roughness ratio, ASLE Trans. 18 (2) (1975) 144-152. 
[7] N. Soda, T. Yamamoto, Effect of tangential traction and roughness on crack initiation/propagation during rolling contact, ASLE Trans. 25 (2) (1982) 198-206.

[8] K. L. Johnson, Contact Mechanics, Cambridge University Press, 1987.

[9] C. Santus, M. Beghini, I. Bartilotta, M. Facchini, Surface and subsurface rolling contact fatigue characteristic depths and proposal of stress indexes, Int. J. Fatigue 45 (2012) 71-81.

[10] H. P. C. O. Swahn, P. C. Becker, O. Vingsbo, Martensite decay during rolling contact fatigue in ball bearings, Metall. Trans. A 7 (8) (1976) 10991110.

[11] I. A. Polonsky, L. M. Keer, On white etching band formation in rolling bearings, J. Mech. Phys. Solids 43 (4) (1995) 637-669.

[12] Q. Y. Wang, C. Bathias, N. Kawagoishi, Q. Chen, Effect of inclusion on subsurface crack initiation and gigacycle fatigue strength, Int. J. Fatigue 24 (12) (2002) 1269-1274.

[13] T. B. Lund, Sub-surface initiated rolling contact fatigue - influence of nonmetallic inclusions, processing history, and operating conditions, J. ASTM Int.l 7 (5) (2010) 1-12.

[14] K. Furumura, Y. Murakami, T. Abe, Development of long life bearing steel for full film lubrication and for poor and contaminated lubrication, Motion Control 1 (1996) 30-36.

[15] S. M. Moghaddam, F. Sadeghi, A review of microstructural alterations around nonmetallic inclusions in bearing steel during rolling contact fatigue, Tribol. Trans. 59 (6) (2016) 1142-1156. 
[16] P. C. Becker, Microstructural changes around non-metallic inclusions caused by rolling-contact fatigue of ball-bearing steels, Met. Technol. 8 (1) (1981) 234-243.

[17] A. Grabulov, U. Ziese, H. W. Zandbergen, TEM/SEM investigation of microstructural changes within the white etching area under rolling contact fatigue and 3-D crack reconstruction by focused ion beam, Scr. Mater. 57 (7) (2007) 635-638.

[18] A. Grabulov, R. Petrov, H. W. Zandbergen, EBSD investigation of the crack initiation and TEM/FIB analyses of the microstructural changes around the cracks formed under rolling contact fatigue (RCF), Int. J. Fatigue $32(3)$ (2010) 576-583.

[19] J. Lai, T. Lund, K. Rydén, A. Gabelli, I. Strandell, The fatigue limit of bearing steels-part i: A pragmatic approach to predict very high cycle fatigue strength, Int. J. Fatigue 38 (2012) 155-168.

[20] M. Cerullo, Sub-surface fatigue crack growth at alumina inclusions in aisi 52100 roller bearings, Procedia Eng. 74 (2014) 333-338.

[21] A. Melander, A finite element study of short cracks with different inclusion types under rolling contact fatigue load, Int. J. Fatigue 19 (1) (1997) 13-24.

[22] M. Nagao, K. Hiraoka, Y. Unigame, Influence of nonmetallic inclusion size on rolling contact fatigue life in bearing steel, Sanyo Tech Rep 12 (1) (2005) $38-45$.

[23] Y. Murakami, Inclusion rating by statistics of extreme values and its application to fatigue strength prediction and quality control of materials., Int. J. Fatigue 3 (18) (1996) 215. 
[24] M. W. J. Lewis, B. Tomkins, A fracture mechanics interpretation of rolling bearing fatigue, Proc. Inst. Mech. Eng., Part J 226 (5) (2012) 389-405.

[25] G. Donzella, M. Faccoli, A. Mazzù, C. Petrogalli, H. Desimone, Influence of inclusion content on rolling contact fatigue in a gear steel: Experimental analysis and predictive modelling, Eng. Fract. Mech. 78 (16) (2011) 27612774 .

[26] K. Hashimoto, T. Fujimatsu, N. Tsunekage, K. Hiraoka, K. Kida, E. C. Santos, Effect of inclusion/matrix interface cavities on internal-fracturetype rolling contact fatigue life, Mater. Des. 32 (10) (2011) 4980-4985.

[27] K. Hashimoto, T. Fujimatsu, N. Tsunekage, K. Hiraoka, K. Kida, E. C. Santos, Study of rolling contact fatigue of bearing steels in relation to various oxide inclusions, Mater. Des. 32 (3) (2011) 1605-1611.

[28] T. J. Baker, K. B. Gave, J. A. Charles, Inclusion deformation and toughness anisotropy in hot-rolled steels, Met. Technol. 3 (1) (1976) 183-193.

[29] F. B. Pickering, Inclusions, Institution of Metallurgists, London, 1979.

[30] A. D. Wilson, The influence of thickness and rolling ratio on the inclusion behavior in plate steels, Metallography 12 (3) (1979) 233-255.

[31] L. Zhang, B. G. Thomas, Inclusions in continuous casting of steel, in: XXIV National Steelmaking Symposium, Morelia, Mich, Mexico, Vol. 26, 2003, p. 28.

[32] P. F. F. Walker, Improving the reliability of highly loaded rolling bearings: the effect of upstream processing on inclusions, Mater. Sci. Technol. 30 (4) (2014) 385-410.

[33] E. Ioannides, An analytical formulation for the life of rolling bearings, acta polytechnica scandinavica, Mechanical Engineering Series. 
[34] F. Guerin, B. Dumon, R. Hambli, Determining the shape parameter of a weibull distribution from mechanical damage models, in: Reliability and Maintainability Symposium, 2001. Proceedings. Annual, IEEE, 2001, pp. $156-160$.

[35] T. A. Harris, Rolling bearing analysis, John Wiley and sons, 2001.

[36] H. Cheng, A numerical solution of the elastohydrodynamic film thickness in an elliptical contact, J. Lubr. Technol. 92 (1) (1970) 155-161.

[37] H. Fu, E. Galindo-Nava, P. E. J. Rivera-Díaz-del Castillo, Modelling and characterisation of stress-induced carbide precipitation in bearing steels under rolling contact fatigue, Acta Mater. 128 (2017) 176-187.

[38] H. Fu, W. Song, E. I. Galindo-Nava, P. E. J. Rivera-Díaz-del Castillo, Strain-induced martensite decay in bearing steels under rolling contact fatigue: modelling and atomic-scale characterisation, Acta Mater. 139 (2017) $163-173$.

[39] H. Fu, P. E. J. Rivera-Díaz-del Castillo, A unified theory for microstructural alterations in bearing steels under rolling contact fatigue, Acta Mater. 155 (2018) 43-55. 